\title{
Study of Time Orientation and Wellbeing in Old Age
}

\author{
Thiyam Kiran Singh ${ }_{1}$, Bharathi Kumari 2 , Pragyendu ${ }_{3}$, Akshat Chowdhury
}

\section{ABSTRACT:}

The present study aimed at exploring time perspective in relation to psychological wellbeing among 90 subjects belonging to 3 different age categories. The time perspective questionnaire ( Zimbardo \& Boyd ,1999) and psychological wellbeing questionnaire ( Bhogle et al, 1995) were administered to a sample of 90 ( 30- Adolescence, 30-Middle Age and 30-Old Age). Data were analyzed with the help of one - way ANOVA and correlation. The results indicated significant differences across 3 age levels in past negative and future areas of time perspective. In past negative area of time perspective the older generation has obtained significantly higher mean than the other two age groups. In future time perspective the younger generation has obtained significantly higher mean. The result also found no significant corelationship between time perspective and wellbeing.

Keywords: Time orientation, Wellbeing, Adolescence, Middle Age, Old Age.

\section{INTRODUCTION}

Although Einstein's theory of relativity established the subjective nature of the physical phenomenon of time, the significance of the psychological interpretation of this relative phenomenon has been a source of controversy among philosophers, psychologists and physical scientists. William James championed the concept of time as so central to psychology that he devoted an entire chapter to "time perception" in The Principles of Psychology. With the later behaviorist revolution came a restricted focus on the behavioral consequences of time-based experiences. This narrow view was rejected of time-based experiences. This narrow view was rejected by Kurt Lewin, whose views are more compatible with those of existential philosophers. Lewin's life space model included the influence of both the past and the future on current behavior. Lewin defined time perspective (TP) as "the totality of the individual's views of his psychological future and psychological past existing at a given time". Contemporary socialcognitive thinking, as represented in Albert Bandura's self-efficacy theory, advances a tripartite temporal influence on behavioural self-regulation as generated by efficacy beliefs grounded in past experiences, current appraisals and reflections on future options.

${ }^{1}$ Assistant Professor, Department of Psychology, AIBAS, Amity University Rajasthan, Jaipur.

${ }^{2}$ Associate Professor, Department of Psychology, Jamia Millia Islamia University.

${ }^{3}$ Assistant Professor, Sri Aurobindo College (eve) Department of Psychology, Delhi University.

${ }^{4}$ Mphil Clinical Psychology trainee, Department of Psychology, AIBAS, Amity University Rajasthan , Jaipur

(C) 2015, K Singh, B Kumari, A Chowdhury; licensee IJIP. This is an Open Access Research distributed under the terms of the Creative Commons Attribution License (http://creativecommons.org/licenses/by/2.0), which permits unrestricted use, distribution, and reproduction in any Medium, provided the original work is properly cited. 
Behavioral gerontologist Laura Carstensen and her colleagues have proposed that the perception of time plays a fundamental role in the selection and pursuit of social goals with important implications for emotion, cognition and motivation. Wellbeing is one of cherished goals of humanity. It refers to state of optimal psychological functioning and experience and defines an idea of "good life". The concept of wellbeing is acknowledged by WHO to be intrinsic to health and to have physical, mental and social dimensions, in the minds of many it is a more explicit recognition that health can be very more than absence of disease or disability. Growth in field of subjective wellbeing(SWB) reflects larger societal trends concerning the individual value, importance of subjective views of evaluating life and recognition that wellbeing necessarily includes positive elements that transcends economic prosperity. The purpose of the study is to find out the past, present and future experiences among adolescence, middle age and old age. People in the socity are not aware much regarding the past, present and future experiences among these groups. People generally avoid old age group as if they are useless, not competent and also thinking that they are at the last stage of life (Bowen \& Skirbekk, 2013). The present study will enlighten about this issue whether it is because of past negative experiences or present or future negative experiences by comparing with adolescence and middle age groups. This study will help to get an idea to policy makers that there is an urgent need to take care of old age groups in improving their negativity in all the domains of past, present and future perspectives.

\section{METHODOLOGY}

Objective: To assess the time perspective and psychological wellbeing across three age group levels.

\section{Sample Size:}

A total of 90 subjects were selected for the study. Thirty adolescents, thirty middle age and thirty old age persons constituted the sample.

\section{Design:}

One way ANOVA was used. The study has one independent variable with three age group levels namely: adolescence, middle and old age. Correlation was used to find out the relationship between time perspective and psychological wellbeing.

\section{Tools used:}

1. Time perspective questionnaire by Zimbardo and boyd (1999)

It comprises of 56 items based on five time perspective dimensions. It is a 5 point rating scale and scoring can be done by adding each item score. Scoring for questionnaires: 9, 24, 25, 41 and 56 are reverse scored. It is easy to administer and score with a clear replicable factor structure, reasonable subscale reliabilities and demonstrated validity. The 5 factors of the 
Zimbardo Time perspective Inventory were established through exploratory and confirmatory factor analysis and demonstrate acceptable internal and test-retest reliability. Convergent, divergent, discriminant and predictive validity are shown by correlational experimental research supplemented by case studies.

2. Psychological well being questionnaire by Bhogle and Prakash (1995)

This questionnaire consists of 28 items. It includes items related to health ,marriage, peer relations, social support, satisfaction with others and self esteem. The responses are dichotomous and are framed in yes or no format. The total score gives the estimation of the psychological wellbeing i.e. higher the score, higher the psychological wellbeing. The test- retest consistency coefficient is 0.84 . This test has satisfactory validity of the questionnaire.

\section{Procedure:}

The subjects were contacted individually for the purpose of the study. Proper rapport was established with the subjects. The middle and old persons were contacted in their home in east of kailash, Delhi and they were asked to fill up the questionnaires. The adolescents were contacted in Sri Aurobindo College and they were asked to fill up the questionnaires. Instructions were explained to the participants and they were asked to give true and honest responses. 


\section{RESULTS:}

Table-1: One way ANOVA for different Factors of Time Perspective of all groups.

\begin{tabular}{|c|c|c|c|c|c|}
\hline \multicolumn{2}{|l|}{ Dimension } & \multirow{2}{*}{$\begin{array}{c}\text { Sum of } \\
\text { Squares } \\
77.35\end{array}$} & \multirow{2}{*}{$\begin{array}{c}\text { Df } \\
2\end{array}$} & \multirow{2}{*}{$\begin{array}{c}\text { Mean Square } \\
38.67\end{array}$} & \multirow{2}{*}{$\begin{array}{c}\mathrm{F} \\
4.48 * *\end{array}$} \\
\hline \multirow[t]{3}{*}{ Past Negative } & Between Groups & & & & \\
\hline & Sources of Variance & 750.96 & 87 & 8.63 & \\
\hline & Total & 828.32 & 89 & & \\
\hline \multirow[t]{3}{*}{ Past Positive } & Between Groups & 16.08 & 2 & 8.04 & \multirow[t]{3}{*}{0.51} \\
\hline & Sources of Variance & 1358.36 & 87 & 15.61 & \\
\hline & Total & 1374.45 & 89 & & \\
\hline \multirow[t]{3}{*}{ Present Fatalistic } & Between Groups & 35.26 & 2 & 17.63 & \multirow[t]{3}{*}{1.20} \\
\hline & Sources of Variance & 1273.23 & 87 & 14.63 & \\
\hline & Total & 1308.50 & 89 & & \\
\hline \multirow[t]{3}{*}{ Present Hedonistic } & Between Groups & 51.80 & 2 & 25.90 & \multirow[t]{3}{*}{1.76} \\
\hline & Sources of Variance & 1276.30 & 87 & 14.67 & \\
\hline & Total & 1328.10 & 89 & & \\
\hline \multirow[t]{3}{*}{ Future } & Between Groups & 135.02 & 2 & 67.51 & \multirow[t]{3}{*}{$4.78 * *$} \\
\hline & Sources of Variance & 1227.46 & 87 & 14.10 & \\
\hline & Total & 1362.48 & 89 & & \\
\hline \multirow[t]{3}{*}{ Total } & Between Groups & 92.07 & 2.00 & 46.03 & \multirow{3}{*}{0.40} \\
\hline & Sources of Variance & 10020.33 & 87.00 & 115.18 & \\
\hline & Total & 10112.40 & 89.00 & & \\
\hline
\end{tabular}

$* p<.05 * * p<.01$

Table shows that the data was analyzed using one way ANOVA for different factors of time perspective. The summary table shows that the older age group differs significantly at past negative $(\mathrm{F}=4.48, \mathrm{P}<0.01 * *)$ and future $(\mathrm{F}=4.78, \mathrm{P}<0.01 * *)$ from the rest of the two age groups. 
Study of Time Orientation and Wellbeing in Old Age

Table-2: One Way ANOVA for Psychological Well-being of all groups.

\begin{tabular}{|l|l|c|c|c|c|}
\hline \multicolumn{2}{|l|}{ Dimension } & $\begin{array}{c}\text { Sum of } \\
\text { Squares }\end{array}$ & Df & Mean Square & F \\
\hline Psychological Wellbeing & Between Groups & 0.82 & 2 & 0.41 & 0.03 \\
\cline { 2 - 5 } & Sources of Variance & 1044.16 & 87 & 12.00 \\
\cline { 2 - 5 } & Total & 1044.98 & 89 & & \\
\hline
\end{tabular}

$* p<.05 * * p<.01$

Table shows summary of the one way ANOVA for psychological wellbeing. The result found no significant difference.

Table-3: Relationship between Dimensions of Time Perspective and Psychological Wellbeing of all groups.

\begin{tabular}{|l|c|}
\hline Dimension of Time Perspective & Psychological Well-being \\
\hline Past Negative & -0.10 \\
\hline Past Positive & 0.02 \\
\hline Present Fatalistic & 0.02 \\
\hline Present Hedonistic & -0.06 \\
\hline Future & 0.03 \\
\hline Total & -0.03 \\
\hline$* p<.05 * * p<.01$ & \\
\hline
\end{tabular}

Table shows relationship between dimension of time perspective and psychological wellbeing of all three groups as a whole. The result found significantly not correlated. 
Table-4: Relationship between Dimensions of Time Perspective and Psychological Wellbeing (Adolescent)

\begin{tabular}{|l|c|}
\hline $\begin{array}{l}\text { Dimension of Time } \\
\text { Perspective }\end{array}$ & Psychological Well-being \\
\hline Past Negative & 0.02 \\
\hline Past Positive & 0.01 \\
\hline Present Fatalistic & 0.08 \\
\hline Present Hedonistic & 0.11 \\
\hline Future & 0.10 \\
\hline Total & 0.11 \\
\hline$* p<.05 * * p<.01$ & \\
\hline
\end{tabular}

Table shows relationship between dimensions of Time Perspective and Psychological Well-being for adolescents. The result found no significant correlation.

Table-5 shows relationships between dimensions of Time Perspective and Psychological well being (Middle Age)

\begin{tabular}{|l|c|}
\hline $\begin{array}{l}\text { Dimension of Time } \\
\text { Perspective }\end{array}$ & Psychological Well-being \\
\hline Past Negative & -0.28 \\
\hline Past Positive & -0.20 \\
\hline Present Fatalistic & -0.13 \\
\hline Present Hedonistic & -0.15 \\
\hline Future & -0.01 \\
\hline Total & -0.28 \\
\hline$* p<.05 * * p<.01$ & \\
\hline
\end{tabular}

Table shows the relationship between time perspective and psychological wellbeing. The result found negatively related to all dimensions. 
Table-6: Relationship between Dimensions of Time Perspective and Psychological Wellbeing (Old Age).

\begin{tabular}{|l|c|}
\hline $\begin{array}{l}\text { Dimension of Time } \\
\text { Perspective }\end{array}$ & Psychological Well-being \\
\hline Past Negative & -0.03 \\
\hline Past Positive & 0.20 \\
\hline Present Fatalistic & 0.12 \\
\hline Present Hedonistic & -0.09 \\
\hline Future & -0.01 \\
\hline Total & 0.08 \\
\hline$* p<.05 * *<.01$ & \\
\hline
\end{tabular}

Table shows that the relationship between dimensions of time perspective and psychological well being. The result found significantly not related.

\section{DISCUSSION:}

The result showed the older age group differs significantly at past negative and future in the dimension of time perspective which means the old age population has more negative past experiences and poor future ideas than middle age population and adolescent population. This may be because old age populations are having less skill with new technologies. Moreover, their ways of coping with stressors are outdated and as a result they are depressed. So, people in the society don't like them. Therefore, old age population were having negative past experiences and also poor future perspectives. Supportively, Rudolf (2007), found out that older adults have poor coping skills with stress and the individual experiences more chronic stressors and favour avoidance coping were more likely to be depressed and have late life drinking problem. Singh (2009) found out that old age people experience loneliness and depression either as a result of living alone or due to lack of close family ties and reduced connections with their culture of origin, which results in an inability to actively participate in the community activities. Desmyter and Raedt (2012) found out that older persons with a past negative perspective were more likely to experience negative affect and depressive feelings, along with a lower level of positive affect and satisfaction with life. 


\section{SUMMARY AND CONCLUSION:}

The present study aimed at exploring time perspective in relation to psychological wellbeing. A total of 90 subjects were selected for the study. These includes thirty adolescents $(\mathrm{N}=30)$, thirty middle -age $(\mathrm{N}=30)$ and thirty old -age $(\mathrm{N}=30)$. The subjects were contacted individually for the purpose of the study. Thus, one - way ANOVA and correlation were used. The tools used were the Time perspective Questionaire by Zimbardo and Boyd (1999) and the Psychological wellbeing Questionnaire by Bhogle and prakash (1995). The result found older age group has significantly more negative past experiences and poor future ideas than middle age population and young adolescent population.

From this study it can be concluded that old age is the stage of life where negative experiences are prominent and also has poor future ideas. This is the stage where relatives and people surroundings neglected them as if they are use for nothing and so on. Their wellbeing is doubtful.

\section{REFERENCES:}

1. Bhogle, S., \& Prakash, I. J. (1995). Development of the psychological well being (PWB) questionnaire. Journal of Personality and Clinical Studies, 11, 5-9

2. Bowen, C.E. , Skirbekk , V. (2013), National Stereotypes of older people's competence are related to older adult's participation in paid and volunteer work. Journals of Gerontology, Series B: Psychological Sciences and Social Sciences , 68 (6): 974-983 . Retrieved from http:// psychsocgerontology. Oxfordjournals.org / content / 68 / 6 / 974.full on 7/11/2014.

3. Desmyter , F., \& Raedt, R. (2012). The Relationship between Time Perspective and Subjective Wellbeing of Older Adults. Journal of Psychologica Belgica, 52 (1), 19-38 . Retrieved from www. Psychologicabelgica.com / article / download / Pb - 52 - 1 -19 / 39 on $6 / 11 / 2014$.

4. Singh , A. , Misra , N. , (2009), Loneliness, Depression and Sociability in Old age . Journal of Industrial Psychiatry, 18(1): 51-55.

5. Rudolf, H.M., Penny, L. B, Kathleen, K. S. \& Bernice S. M. (2007). Older adults' coping with negative life events: Common Processes of Managing Health, Interpersonal, and Financial/Work Stressors. International Journal of Aging Human Development, 62(1): 39-59. Retrieved from http://www.ncbi.nlm.nih.gov/pmc/articles/PMC1948895/ on $5 / 11 / 2014$.

6. Zimbardo, P.G., \& Boyd, J.N. (1999). Development of Time Perspective Questionaire. The Time Paradox : Using The New Psychology of Time to your Advantage. New York: Penguin Press. 